\title{
Personality Science: United in Diversity \\ Inaugural Editorial for the New Journal "Personality Science"
}

\author{
John F. Rauthmann ${ }^{\text {a }}$ (D) \\ [a] Department of Psychology, Bielefeld University, Bielefeld, Germany.
}

Citation: Rauthmann, J. F. (2020). Personality science: United in diversity. Inaugural editorial for the new journal "Personality Science". Personality Science, 1(1), Article e5297. https://doi.org/10.5964/ps.5297

Published (VoR): 2020-12-23

Corresponding Author: John F. Rauthmann, Department of Psychology, Bielefeld University, Universitätsstraße 25, 33615 Bielefeld, Germany. E-mail: editors@ps.psychopen.eu

\section{Key Insights}

- Introducing the new journal Personality Science (PS)

- Online-only and full open-access, without author or reader fees

- Aims to provide a top-quality and multidisciplinary outlet for personality science

- Seeks to foster diversity and inclusion in the community of personality scientists

- Implements rigorous guidelines to ensure transparency, openness, and reproducibility

- Features exciting paper formats

- Journal website: ps.psychopen.eu

No doors should be closed in the study of personality. - Gordon Allport (1946, pp. 133-134)

The study of personality and individual differences is diverse, vibrant, and productive. It is essentially the scientific inquiry into human nature and its diversity (Cloninger, 2020; Hogan \& Sherman, 2020; Larsen \& Buss, 2021) and thus has been rightfully referred to as a hub science (Morf, 2002; Yang \& Chiu, 2009). As a hub, it has the potential to link different psychological and non-psychological disciplines to each other in the common quest to understand persons, including describing, predicting, and explaining what they think, feel, want, and do in general ( traits) and at the moment ( states). Indeed, personality psychology, as a subfield of psychological science, has a considerable bandwidth by seeking to conceptualize, measure, and study human differences and all their consequences for who persons are and how they live their lives. These differences can be enduring or momentary, and non-pathological or pathological. They can be captured be- 
tween persons (interindividual perspective), within persons (intraindividual perspective), and even at the group-level (e.g., cross-cultural differences in traits). Further, they may pertain to biological, psychological, and social origins, expressions, structures, dynamics, processes, mechanisms, functioning, development, and consequences. There are a myriad of personality-relevant psychological variables alone (e.g., perceptual, cognitive, affective, motivational, volitional, regulatory, behavioral) that need to be measured, put into relation to biological and environmental constraints, and integrated to study a whole person. In this vein, Revelle (2007, p. 37) opined that "[p]ersonality research is the last refuge of the generalist in psychology". The scope of a broader personality-centered science expands even more by also including variations between and within animals or entire species (e.g., Bell et al., 2009; Carere \& Maestripieri, 2013; Dall et al., 2004; O'Dea et al., 2020; Sih et al., 2004, 2015, 2020; Wolf \& Weissing, 2012), virtual avatars and intelligent systems (e.g., Bélisle \& Bodur, 2010; Fong \& Mar, 2015; McLeod et al., 2014; Pan et al., 2015; Read \& Miller, 2002; Ünal et al., 2018), and robots (e.g., Bremner et al., 2016; Broadbent et al., 2013; Churamani et al., 2020; Craenen et al., 2018; Reich \& Eyssel, 2013; Robert, 2018). Thus, there is a rich smorgasbord of topics, phenomena, and variables that a science of personality can tackle - with an equally staggering array of perspectives, theories, questions, methodologies, and applications. It is this diversity that this new journal wants to celebrate and cultivate.

Personality Science $(P S)$ is an online-only, full open-access journal, owned by the European Association of Personality Psychology (EAPP $)^{1}$ and published within the PsychOpen GOLD program of the Leibniz Institute for Psychology (ZPID) ${ }^{2}$. It aspires to be a premiere outlet for any insights on personality and individual differences - cutting across traditional disciplinary borders. Personality-relevant topics are often studied in psychology, but they are equally relevant in other disciplines (e.g., genetics, neuroscience, medicine, computer science, economics, political science, anthropology, sociology, cultural studies, linguistics, educational science, philosophy, history, etc.). It is thus our aim to capitalize on the diversity of approaches to studying personality and help unify the field of a personality-centered science.

This inaugural editorial serves several purposes. First, it seeks to underscore the importance of diversity in the scientific study of personality. Second, it introduces the mission and visions of this new journal. Third, it provides prospective readers, authors, and reviewers with useful information on the modalities of the journal. We hope that PS will become an attractive and inspiring outlet for rigorous, transparent, and impactful work on personality and individual differences, without any barriers to reading and publishing papers in it.

\footnotetext{
1) See https://eapp.org/

2) See https://www.psychopen.eu/
} 


\section{A New Journal}

\section{The Need for Another Journal}

$P S$ was founded to (1) respond to a changing publishing landscape, (2) experiment with novel publishing and paper formats, and (3) incentivize emerging best practices and scientific standards. First, more journals are moving towards online-only publications (or at least prioritize print publications less) and adopting open-access options, but to varying degrees and often with article processing charges (APCs). APCs defray costs of production and guarantee that an article is not hidden behind a paywall. Several journals offer limited amounts of partial or even full waivers on these APCs, and some countries or institutions have certain funds and deals in place to pay for APCs. However, journals neither charging authors nor readers are still relatively rare. These are referred to as no-fee, platinum, or diamond open-access journals. With PS, we aim to provide such an online-only, no-fee journal for personality science that is credible and selective in what it publishes. Further, we hope that the lack of financial barriers to reading and publishing in $P S$ will contribute to more diversity and inclusion.

Second, $P S$ was devised to be a flexible journal that can experiment with novel publishing and paper formats. This is usually not possible with "traditional" print journals owned by corporate publishers that need to consider profit calculations (PS does not generate any revenue). Science is changing in the way it generates and disseminates knowledge, and so a journal that can rapidly adapt to the changing landscape is needed. Consequently, we aim to continually improve the journal and be responsive to readers', authors', reviewers', and editors' ideas and feedback. ${ }^{3}$

Third, PS aims to promote and incentivize emerging best scientific practices, acknowledging that good, reproducible, and transparent science is hard but worth the effort on many levels (e.g., Munafò et al., 2017; Nosek et al., 2019); may entail conducting "slower science" (e.g., Vazire, 2018); and will need to involve more collaborative effort among researchers from different research groups, disciplines, and countries (e.g., Chartier et al., 2018; Kliegl \& Bates, 2011; Moshontz et al., 2018). In this vein, the journal calls for more implementations of transparency and open science; precision, rigor, and formalization; cogent use of sophisticated data-analytical strategies; and theory-building. Further, $P S$ seeks to facilitate a more multidisciplinary understanding of personality as well as foster more diversity and inclusion in the community of personality scientists.

\section{Mission and Vision}

At $P S$, we aim to quickly respond to changing scientific best practices and provide a community-driven publishing outlet. We are neither subject to corporate publisher

3) To give feedback, please visit https://ps.psychopen.eu/index.php/ps/feedback 
requirements (e.g., needing to make profit off papers) nor to problematic infrastructural constraints that could impede scientific soundness (e.g., needing to achieve a benchmark journal impact factor). Our sole prerogative is to provide a top-quality and inclusive outlet for personality science. In doing so, the journal's main goals concern three different forms of expansion: (1) expanding the field beyond psychology, (2) expanding the public profile of the field, and (3) expanding the scope and amount diversity in the field.

\section{Expanding the Field}

The study of something as complex as personality can transcend the discipline of psychology, so this journal provides a great opportunity to join forces. Historically, however, much of personality science is rooted in personality psychology. Indeed, one may argue that personality psychology is central to psychology itself, which is essentially interested in different aspects of a person. Etymologically, the ancient Greek word $\psi v \chi \eta \dot{\eta}\left[p s u k^{h} \bar{e}\right]$ meant "breath" and "life," but also took the meanings of "mind, soul, spirit" and even "personality" (Liddell \& Scott, 1940). Not surprisingly, early pioneers in the emerging science of psycho-logy - such as Francis Galton, William James, Sigmund Freud, and Alfred Binet - were interested in rather enduring characteristics of persons, such as temperament, motives, or cognitive abilities. Indeed, many of the 100 most eminent psychologists of all time (Diener et al., 2014; Haggbloom et al., 2002) have, at some point in their careers, conducted research on personality and individual differences. Among them are Gordon Allport, Albert Bandura, Raymond B. Cattell, Hans J. Eysenck, and Carl Rogers. ${ }^{4}$ And to this day, it is especially personality psychologists who are equipped to study the "whole person" and the coherent integration of different variables or systems within individuals (e.g., Fournier et al., 2015; Funder, 2015; McAdams, 1997a, 1997b; McAdams \& Pals, 2006; Morf, 2002; Renner \& Laux, 2000; Stern, 1923). In light of such a scope, some believe that personality-psychological knowledge could form the core of psychology in general (Allport, 1961). This idea fits to bibliometric analyses indicating strong citation rates of personality-psychological papers (Allik, 2013) and that personality/social psychological articles are located at the "heart" of psychological citation networks (Yang \& Chiu, 2009). To conclude that personality psychology really is the core of psychology may be an overstretch, of course. Notwithstanding, the notion is understandable because the topics, questions, methodologies, and applications of personality psychology are diverse (Revelle, 2007; Robins et al., 2007; Tracy et al., 2009) and have the potential to tie together different psychological subdisciplines.

\footnotetext{
4) Some of them have repeatedly come under scrutiny for allegations of questionable research practices (including violations of research ethics) and endorsements of ethically questionable attitudes (e.g., racism, eugenics). Their listing here should not be taken as an endorsement of them and their work. Rather, they have been listed because they objectively are well-known and well-cited across all psychological disciplines and did have a lasting influence on certain areas of personality psychology.
} 
This diversity, however, needs to be better harnessed which PS aspires to do in two ways: within personality psychology and beyond it. First, for quite some time, a splintering has been going on in personality psychology, insulating certain research topics (e.g., self and identity, intelligence, attitudes, virtues, personality disorders, competencies) from "mainstream" personality psychology. These topics now form separate fields with their own journals, learned societies, and publication networks (e.g., intelligence), or they have flocked to other psychological subdisciplines (e.g., competencies and skills to I/O psychology). Fortunately, there have recently been increased efforts at integrations (e.g., personality psychopathology: DeYoung et al., 2020; Tackett et al., 2016; personality traits and ability: Colom et al., 2019), which PS seeks to propel even further. Nonetheless, the reality is that personality psychology is fragmented and far from a homogeneous or unified subdiscipline of psychology (e.g., Lanning, 2017). Rather than seeing this as a problem, $P S$ wants to leverage the inherent diversity in studying personality and individual differences and treat it as a strength. This journal thus aims to provide an attractive and inclusive home for everyone interested in personality or individual differences, regardless of the psychological discipline(s) they identify with. This can help expand but also consolidate personality psychology as a field in psychology.

Second, because "personality" is a complex phenomenon, personality psychology needs to be integrative, synthetic, and holistic (McAdams \& Pals, 2006, 2007). As Morf (2002, p. 649) aptly put it, "[p]ersonality psychology has a focus on understanding the functioning of the person as a whole, and is thus located at the hub of the other subdisciplines of psychology and related sciences devoted to the study of human nature". Personality psychology can benefit from the input of other psychological subdisciplines and other scientific disciplines - and also vice versa. Increasing collaborative efforts between disciplines can yield several beneficial outcomes, such as gaining new knowledge and insights, expanding traditional ways of thinking and working, serving a larger and more diverse community, counteracting isolated research endeavors, and mitigating the problematic use of methods (Devezer et al., 2019; Green \& Johnson, 2015; Smaldino \& O'Connor, 2020). However, to be truly successful, personality science not only needs to be rigorous, credible, and cumulative, it will also need to be open, collaborative, and inclusive. Correspondingly, a special focus of PS lies on building a community of scholars interested broadly in personality and individual differences of humans, animals, avatars, or robots - regardless of scientific discipline. The journal thus seeks to encourage more cross-talk and cross-fertilization between disciplines to study personality-relevant topics from different perspectives.

In sum, $P S$ seeks to be an outlet for any kind of personality-centered work. In keeping with the mission to expand personality science beyond any disciplinary boundaries, $P S$ explicitly encourages contributions from any scientific field. This will hopefully lead to importing insights from other scientific disciplines, while also enriching them by exporting personality-psychological knowledge. This process can help grow a larger, more di- 
verse and inclusive community of personality scientists. The idea is to gradually progress from a multidisciplinary perspective (i.e., studying the same phenomena through the lens of different disciplines) to an inter- or transdisciplinary science of personality (i.e., blending the different disciplines to become a new cross-cutting one; Stember, 1991) ${ }^{5}$. PS seeks to facilitate and accelerate this process.

\section{Expanding the Public Profile of the Field}

Personality differences have ubiquitous and far-reaching consequences, for example, for learning in school, leisure time activities, job selection and satisfaction, leadership, interpersonal attraction and relationships, physical and mental health, purchase decisions and spending, voting, well-being, aging, and longevity. Several studies and meta-analyses have demonstrated this robust and replicable "power of personality" on a plethora of real-world outcomes in the personal, social, and occupational domain (Beck \& Jackson, 2020; Hogan, 2007; Ozer \& Benet-Martínez, 2006; Roberts et al., 2007; Soto, 2019, in press). It thus stands to reason that personality-scientific insights could have important and lasting impacts on institutions and policies (e.g., in education, insurance and health sectors, social services, business and organizations; see Bleidorn et al., 2019; Hengartner et al., 2016; cf. IJzerman et al., 2020). However, such insights need to be properly broadcasted and exported to the public.

In keeping with the mission of expanding the reach of personality science to the public, $P S$ explicitly welcomes applied papers that are geared towards solving practical problems "in the real world", can contribute to public discourse, or concern how personality-scientific insights can inform, and be informed by, societal and geo-political issues, public interest, and practice. PS thus seeks to open up the field to a wider readership beyond academic researchers, such as practitioners, policy-makers, NGOs, industry, and international institutions. Further, the journal and selected papers will be regularly promoted on online social media platforms to increase reach and dissemination. ${ }^{6}$

\section{Expanding Diversities in the Field}

In many ways, diversity stands at the heart of personality science, which is the discipline concerned with diversity and individual uniqueness. To do that scope justice, we need diversity in who partakes in our science and how our science is conducted. Diversity has many benefits (Page, 2008) and thus is a core concern of PS. As Medin et al. (2017) point out, diversity should be sought in samples, researchers, and methodologies. These are also the three pillars PS aims to tackle.

First, diversity in the samples studied in empirical work is important. Many psychological studies - and this includes those from personality psychology - rely on cross-section-

5) Examples for transdisciplinary endeavors are the fields of cognitive science, public health, or artificial intelligence.

6) The journal can be followed on Twitter (@PersSciJrnl). 
al self-report data from convenience samples. In essence, many findings in the literature pertain to what younger, female students at higher education institutions in Western countries (most often North America) report about themselves at certain points in time. If we are interested either in generalizing our findings across populations or explaining why and when there are meaningful differences between populations, then different samples need to be used to probe constraints on generality (Simons et al., 2017). The lack of diversity and representativeness in human samples has already been understood and openly called out several times (Arnett, 2008; Rad et al., 2018; Thalmayer et al., 2020), most notably in the conclusion that participants are predominantly from "WEIRD" countries - Western, educated, industrialized, rich, and democratic (Henrich et al., 2010). Although some progress has already been made (e.g., Apicella et al., 2020), we still need to do better. Hence, $P S$ will treat papers with less WEIRD samples (e.g., those that include immigrants and cultural minorities, individuals with less income or lower education, participants from different countries, etc.) as important. Additionally, all papers need to clearly describe their samples and discuss potential boundaries of the generalizability of findings.

Second, diversity in those conducting research is important. To date, US-American researchers still dominate psychological science (Cheek, 2017). In personality psychology, especially North America and Central Europe are dominant forces, while the salience and impact of researchers from other countries (e.g., from South America, Africa, Asia, and Oceania) still seem to lag behind. Although the reasons for such "nation gaps" may be varied (e.g., Allik et al., 2020; Harzing \& Giroud, 2014; Thelwall \& Levitt, 2018), the lack of diversity in researchers could be detrimental to the field of personality science. For example, an empirical study from Hofstra et al. (2020) on $~ 1.2$ million US doctoral recipients (1977-2015) indicated that higher rates of innovation and novelty could be expected specifically from demographically underrepresented and minority groups, though their contributions seemed to have been less impactful and discounted more. Another study by AlShebli et al. (2018), analyzing $\sim 9$ million papers and $\sim 6$ million scientists, showed that more ethnic diversity was associated with more citations and hence scientific impact (relative to more ethnic homogeneity). PS aspires to be a catalyst for more diverse community-building to increase equal opportunities, enrich the scientific discourse, facilitate ties and collaborations between different scientists, and ultimately strengthen the impact of personality science.

Third, diversity in scientific approaches (e.g., perspectives, theories, questions, methodologies, etc.) is important. In a simulation, Devezer et al. (2019) showed that different types of scientists, subscribing each to a different dominant research strategy (epistemic diversity), performed better in several areas (e.g., reproducibility, time until finding the truth, etc.) than when only one homogeneous type worked towards finding a true model. In another computational experiment, Hong and Page (2004) showed that, because of their diversity in problem-solving, randomly selected problem-solving teams could 
outperform teams of best-performers. In a further mathematical model, Smaldino and O'Connor (2020) demonstrated that methodological improvements could be spurred by incorporating feedback from outside disciplines (see also Expansion of the Field above). Taken together, diversity in research approaches could buffer shortcomings of single research strategies, increase the competent use of good methods, expand the realm of questions asked, accelerate scientific discovery, and help arrive at more reproducible and "true" findings more efficiently. While increasing diversity in researchers should also contribute to increased diversity in scientific approaches, the adoption of different approaches still needs to be systemically encouraged - which PS explicitly does.

Of course, none of the above studies explicitly focused on personality scientists. However, there is little reason to believe that their key findings are not at least in some parts generalizable. Their messages should thus ring loud and clear to us: We ought to diversify samples, researchers, and methodologies in personality science, and this entails creating a more inclusive and collaborative space where everyone - and especially hitherto underrepresented groups - can partake. This will be the path to efficiently and effectively building a more credible, innovative, and ultimately successful personality science. $P S$ seeks to be a driving force in establishing such a path.

\section{Values and Standards}

To provide a strong and attractive journal, $P S$ commits to the eight core values of (1) diversity and inclusion of contributors; (2) topical breadth; (3) multidisciplinarity; (4) transparency, openness, and fairness in all matters; (5) conceptual clarity and terminological precision; (6) rigorousness of methods and statistics; (7) replicability, robustness, and generalizability of insights; and (8) utility, impact, and broadcasting of robust insights to the public. Details can be found in Table 1 and the journal website.

A vital concern for PS is the implementation of transparency and openness in research articles. To ensure certain standards across the data-reporting papers that PS publishes, the Transparency and Openness Promotion (TOP) Guidelines ${ }^{7}$ are adopted. The TOP Guidelines contain eight modular standards that can be implemented at three different levels (with Level 1 being the least, and Level 3 the most rigorous option). $P S$ is committed to following Levels 2 and 3 of the TOP modules, as outlined in Table 2. Empirical articles will be screened for their adherence to these standards, and Open Science badges $^{8}$ will be available for eligible papers. To ensure that empirical findings are independently reproducible (and potentially replicable), any supplements of accepted papers (e.g., pre-registrations; materials: stimuli, questionnaires, tests, etc.; codebooks; analysis scripts, code, or syntax; raw and/or processed data; additional analyses: e.g.,

\footnotetext{
7) See https://cos.io/top

8) See https://www.cos.io/initiatives/badges 


\section{Table 1}

Core Values of Personality Science

\begin{tabular}{|c|c|}
\hline Value & Consequence for the Journal \\
\hline $\begin{array}{l}\text { Diversity and inclusion of } \\
\text { contributors }\end{array}$ & $\begin{array}{l}\text { The journal strives for diversity and inclusion regarding its editorial team, } \\
\text { reviewers, and authors, with a special emphasis on including scholars from } \\
\text { underrepresented regions. }\end{array}$ \\
\hline Topical breadth & $\begin{array}{l}\text { The journal does not restrict any topics so long as they pertain to } \\
\text { personality and individual differences. }\end{array}$ \\
\hline Multidisciplinarity & $\begin{array}{l}\text { The journal encourages publications from disciplines other than psychology } \\
\text { or from multidisciplinary consortia. Over time, the journal's } \\
\text { multidisciplinary focus should contribute to inter- and transdisciplinary } \\
\text { approaches. }\end{array}$ \\
\hline $\begin{array}{l}\text { Transparency, openness, and } \\
\text { fairness in all matters }\end{array}$ & $\begin{array}{l}\text { The journal adheres to scientific and ethical best practices (e.g., adopting } \\
\text { TOP Guidelines) and continuously strives to update itself and implement } \\
\text { cutting-edge solutions that ensure transparency, openness, and fairness. }\end{array}$ \\
\hline $\begin{array}{l}\text { Conceptual clarity and } \\
\text { terminological precision }\end{array}$ & $\begin{array}{l}\text { Papers need to be written concisely and clearly (intended for a wide } \\
\text { audience), with a special emphasis on precise and consistent terminology to } \\
\text { avoid jingle-jangle fallacies. }\end{array}$ \\
\hline $\begin{array}{l}\text { Rigorousness of methods and } \\
\text { statistics }\end{array}$ & $\begin{array}{l}\text { Papers with empirical data need to meet the highest quality standards } \\
\text { regarding methods and statistics. }\end{array}$ \\
\hline $\begin{array}{l}\text { Replicability, robustness, and } \\
\text { generalizability of insights }\end{array}$ & $\begin{array}{l}\text { The journal aims to contribute towards building a strong and cumulative } \\
\text { knowledge base for personality science by publishing replication studies, } \\
\text { registered reports, and papers indicating the (boundaries of the) } \\
\text { generalizability of their findings, methods, or theories. }\end{array}$ \\
\hline $\begin{array}{l}\text { Utility, impact, and broadcasting } \\
\text { of robust insights to the public }\end{array}$ & $\begin{array}{l}\text { The journal aims to broadcast personality science better to the public so that } \\
\text { personality-scientific knowledge can inform real-world issues. }\end{array}$ \\
\hline
\end{tabular}

tables, figures; multimedia; any other files) need to be uploaded to PsychArchives, a product of ZPID via long-term public funding. ${ }^{9}$ This online repository can be used to preserve and make freely available a variety of digital research objects according to the FAIR principles (i.e., files should be findable, accessible, interoperable, and reusable). PS has partnered up with PsychArchives because of its many benefits. Among them is that the repository is not vulnerable to commercial risks and can thus guarantee the permanent and unaltered availability of files. Further, files obtain a persistent digital 
Table 2

Implementation of TOP Guidelines in Personality Science

\begin{tabular}{|c|c|c|}
\hline Modular Standard & Level & Implementation in the Journal \\
\hline Citation Standard & 3 & $\begin{array}{l}\text { An article is not published until providing appropriate citation for data } \\
\text { and materials. }\end{array}$ \\
\hline Data Transparency & 2 & $\begin{array}{l}\text { Data must be posted to a trusted repository. } \\
\text { Exceptions must be identified at article submission. }\end{array}$ \\
\hline Analytical Methods & 2 & Code must be posted to a trusted repository. \\
\hline Transparency & & Exceptions must be identified at article submission. \\
\hline Research Materials & 2 & Materials must be posted to a trusted repository. \\
\hline Transparency & & Exceptions must be identified at article submission. \\
\hline $\begin{array}{l}\text { Design and Analysis } \\
\text { Transparency }\end{array}$ & 3 & $\begin{array}{l}\text { The journal requires and enforces adherence to design transparency } \\
\text { standards for review and publication. }\end{array}$ \\
\hline Pre-registration of Studies & 2 & $\begin{array}{l}\text { An article states whether pre-registration of a study exists, and, if so, } \\
\text { allows access during peer review for verification. }\end{array}$ \\
\hline $\begin{array}{l}\text { Pre-registration of Analysis } \\
\text { Plans }\end{array}$ & 2 & $\begin{array}{l}\text { An article states whether pre-registration with an analysis plan exists, } \\
\text { and, if so, allows access during peer review for verification. }\end{array}$ \\
\hline Replication & 3 & $\begin{array}{l}\text { The journal uses Registered Reports }{ }^{\mathrm{a}} \text { as a submission option for } \\
\text { replication studies with peer review prior to observing any study } \\
\text { outcomes. }\end{array}$ \\
\hline
\end{tabular}

Note. The TOP factor of Personality Science can be found at https://topfactor.org/

${ }^{a} P S$ encourages the submission of Registered Reports not just for replication studies.

object identifier (DOI) and are enriched with comprehensive metadata which increases their discoverability and reusability. Lastly, PsychArchives employs strict user guidelines and can thus ensure consistent and rigorous quality standards across the board.

9) See https://www.psycharchives.org/. At the launch of the journal, authors do not need to have uploaded their supplements themselves to PsychArchives. When submitting an article, supplements should be available on any open repository so that they can also be reviewed. If a paper is publishable, a conditional acceptance will be rendered that asks for all necessary supplements to be uploaded to the journal's submission system. After checking these files and also establishing badge eligibility, a full acceptance will be rendered. Next, journal staff will upload the supplements to PsychArchives and include the new URLs in the copy-edited manuscript. Authors will then receive a proof of their article with the URLs to their supplements on PsychArchives. 


\section{Modalities of the Journal}

\section{What Personality Science Publishes}

\section{Content and Scope}

In accordance with our inclusive understanding of personality science, $P S$ aims to provide an outlet for all scholars interested in personality and individual differences (in humans, animals, virtual avatars, robots, etc.), broadly construed. ${ }^{10}$ In general, PS publishes theoretical, methodological, empirical, and applied papers on the origins, expressions, structures, dynamics, processes, mechanisms, functioning, development, and consequences of nonpathological and pathological personality as well as their definition, operationalization, assessment, and potential applications. The scientific examination of human, animal, or artificial/virtual personality is not confined to any (a) specific paradigm (e.g., psychodynamic, learn-theoretical, humanistic, cognitive, trait-theoretical, biological, transactional), (b) methodology (e.g., quantitative, qualitative, mixed-methods), (c) type of research (basic, applied), or (d) domain of individual differences (e.g., neurobiological structures, body characteristics, temperament, lexical traits, intelligence, abilities, aptitudes, motives, needs, goals, interests, regulation, values, attitudes, virtues, well-being, personal environments and relationships, self-variables, identities, etc.) or group-level differences (e.g., sex and gender differences; country, nation, or ethno-cultural differences). Accordingly, PS publishes a diverse array of topics that showcase how rich the field is. It thus seeks to provide a worldwide forum for scientists, teachers, and practitioners who are interested in the scientific study of personality and individual differences.

\section{Paper Formats}

All papers are featured in a short- to middle-length style (with specific recommendations for the number of words, references, tables, and figures), and they may be submitted without prior solicitation (i.e., uninvited) or in response to a specific invitation. Papers can be submitted any time, and they are published online-only on a continuous basis (i.e., there is no traditional volume or issue ordering). At the time of launching the journal, there are five different paper categories (Theory, Methodology, Empirical, Applied, Comment) and eight special paper types (State of the Art Review, Tutorial, Projects \& Data, Insights \& Ideas, Cumulative Blitz Report, Registered Report, Replication, Meta-analysis). A summary can be found in Table 3. All papers will fall into one category, and some may also have a special type.

10) Authors wishing to submit should familiarize themselves with https://ps.psychopen.eu/index.php/ps/author-guidelines and https://ps.psychopen.eu/index.php/ps/about/submissions 


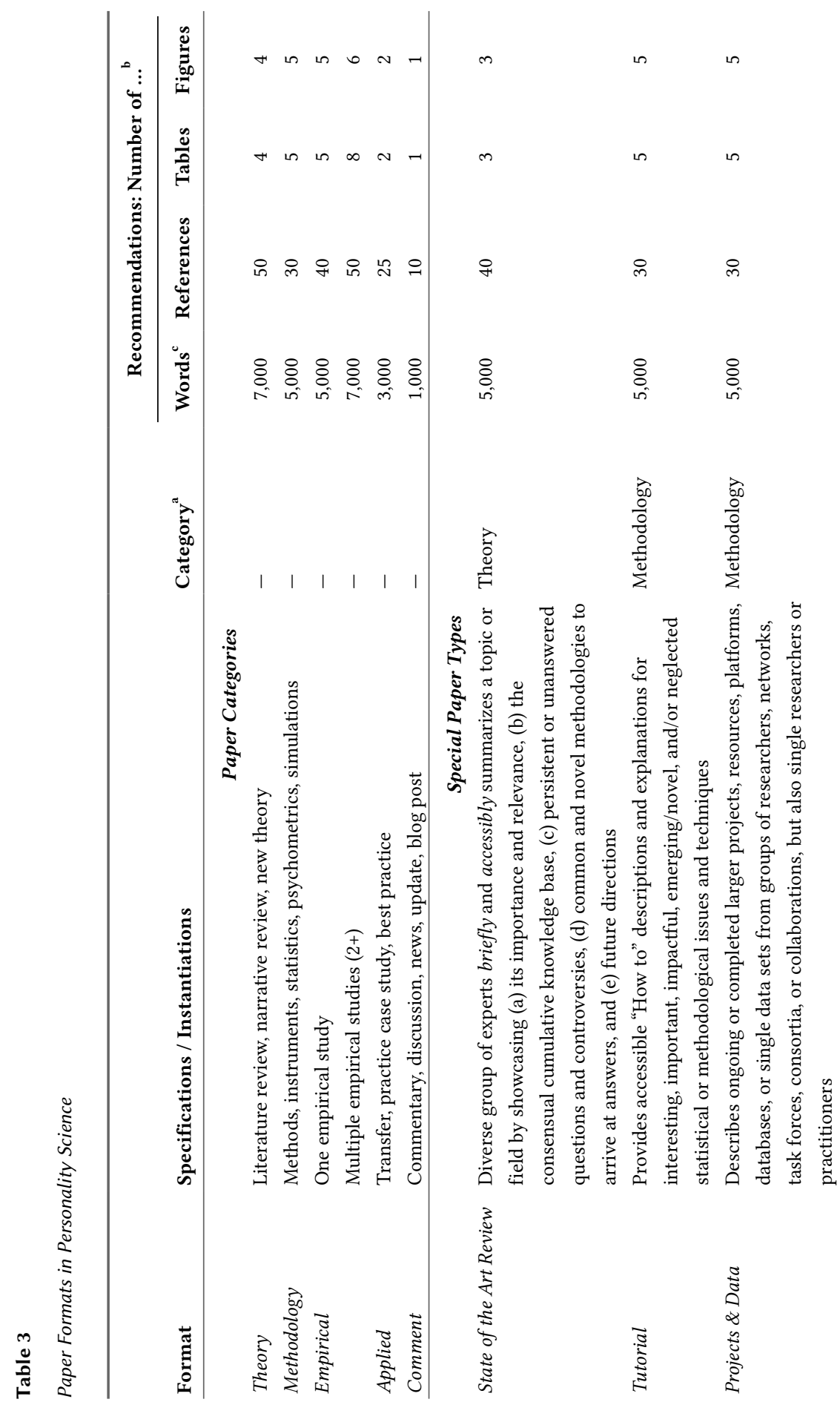




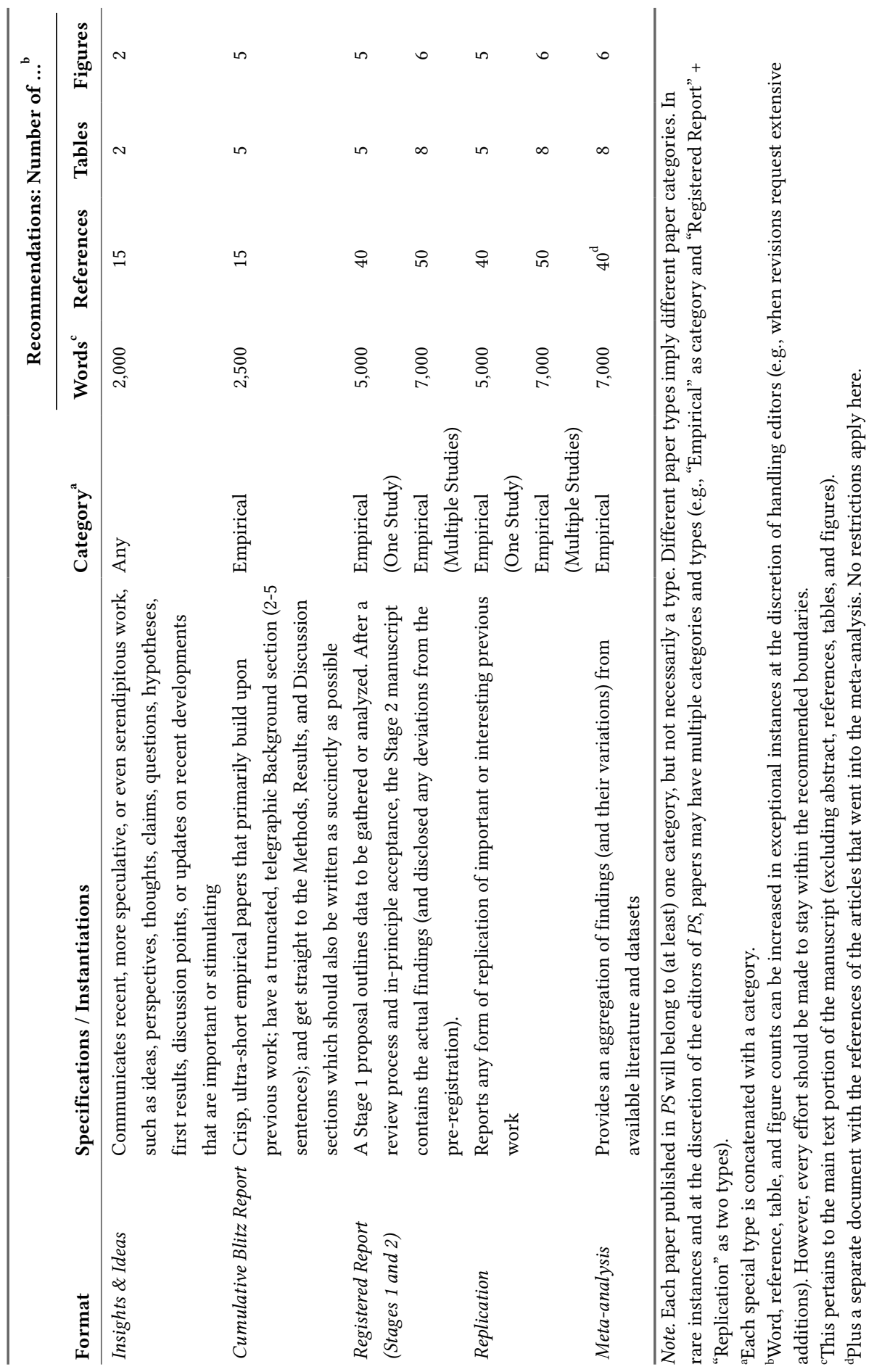


Papers can also be published alongside each other in a collection. Such collections feature a set of papers that are thematically linked and may also refer to or discuss each other. Each paper obtains its own DOI (and is of course separately citable) but will be marked as belonging to a collection. Currently, PS offers two types of collections. In "Theme Bundles", papers (regardless of their category or type) are linked together because of a common phenomenon, issue, topic, perspective, theory, method, or application. In "Controversy Exchanges", controversial issues are tackled from researchers or teams with opposing views that each (try to) make their case as compellingly as possible. These exchanges may be accompanied by a synthesis or rejoinder from a third (and more neutral) party or simply contain a back-and-forth between the factions. We believe this can be an exciting venue for authors and readers alike as disagreements (and their reasons) are sometimes not directly spelled out and openly discussed in the literature, making it hard to detect, navigate, or appropriately deal with them.

\section{Empirical Work}

$P S$ is interested in any kind of empirical work, including but not limited to following parameters: research type (basic, applied), designs (e.g., cross-sectional, longitudinal, experimental, quasi-experimental; laboratory, field; etc.), samples (e.g., case study; homogeneous vs. heterogenous sample; children, adolescents, adults, older aged; twins; multi-group; samples from different countries or regions; without vs. with clinical diagnosis; etc.), types of data (quantitative, qualitative, mixed-methods), data sources (e.g., behaviors and their traces offline, online, or in archives; indirect measures; observations via experts; physio-biological, neurological, and genetic information; strangers' impressions; informants' knowledge; experience sampling; self-reports), special analyses (e.g., metaanalysis, mega-analysis), or statistical frameworks (e.g., frequentist, Bayesian). Regardless of the specifics, articles reporting data should generally be of the highest quality in terms of precision, rigor, transparency, and potential contribution to the literature. Empirical articles need to clearly distinguish between exploratory and confirmatory hypotheses, include several statements pertaining to openness and transparency, discuss boundary conditions to the generalizability of their findings, and provide (as far as possible) data, code, and materials a supplements so that findings can be reproduced and perhaps replicated in further research. Further, "failed" replications, null findings, and a messy set of findings are publishable in PS, provided that these findings are not a function of methodological or statistical shortcomings and that they provide a meaningful contribution to the literature.

\section{Special Encouragements}

$P S$ is devised to be open and inclusive, and we hope prospective authors will take advantage of that. Here, we list kinds of papers that could be exciting to readers and the field of personality science (see Table 3 for details on all categories and types of papers). This 
does not mean that such papers would be treated preferentially or differently; rather, we want to emphasize here that we also explicitly encourage such submissions.

First, replications of important or interesting effects, ideally pre-registered and perhaps even multi-site or consortium-authored ("many-labs"-type research: e.g., Ebersole et al., 2020; Klein et al., 2018), are explicitly encouraged. PS generally seeks to publish papers that provide robust evidence, quantify or discuss robustness and its boundary conditions, and contribute to a credible and cumulative knowledge base. As such, whether replications "worked" or not is not a primary concern so long as methodological and statistical rigor have been upheld.

Second, PS offers Registered Reports where a Stage 1 proposal is peer-reviewed before any outcomes have been observed (i.e., before any data have been gathered or analyzed). ${ }^{11}$ Such a proposal can garner an in-principle acceptance and will then be formally pre-registered and frozen at PsychArchives. A Stage 2 manuscript will then be publishable regardless of any outcomes (so long as the pre-registered plans have been followed appropriately). Such a Registered Report format may not only increase credibility but also rigor and quality of papers with no costs to novelty or creativity (for initial evidence, see Soderberg et al., 2020).

Third, there are certain kinds of papers that may be difficult to publish in a more traditional journal, and we want these to be able to find a home in PS. For example, a description of an ongoing or past empirical project; an interesting dataset or database; or a platform for research, testing, or teaching resources for the field (e.g., Atherton \& Robins, 2020; Kandler et al., 2019; Spadaro et al., 2020) can be submitted as a Projects \& Data paper type to stimulate collaboration and help dissemination. An exciting yet not fully cooked idea or preliminary but important analysis can be submitted as an Insights \& Ideas paper type, serving as a short communication of a "eureka" moment. A blog-type post of wide interest could be submitted as a Comment or a Tutorial paper type, depending on what it aims to achieve (e.g., inform vs. teach).

Lastly, work from consortia or large-scale collaborative networks (e.g., Graham et al., 2020; Joel et al., 2020) are explicitly welcome in PS. These pool resources to conduct powerful and coordinated analyses and to empirically examine boundary conditions of generality (Simons et al., 2017). Collaboration - not just within a discipline but also across multiple disciplines - will become increasingly important to provide robust and generalizable evidence for empirical patterns of findings. PS hopes to be at the forefront of publishing collaborative efforts, be they in formalized consortia, loose groups of collaborators, crowdsourcing networks, or adversarial collaborations.

11) In fact, PS offers two types of Registered Reports: (1) before any data have been gathered (Registered Report Pre-Data) or (2) before already existing data have been examined and analyzed (Registered Report-Post-Data). The type will be indicated transparently on the published paper. 


\section{Discouragements}

In general, $P S$ strives to be as open as possible, but there are certain kinds of papers that we discourage and are only considered under rare circumstances. First, any longer paper (i.e., more than 7,000 words plain text in the initial submission) will usually not be considered. ${ }^{12}$ Second, most scale development papers or translations of scales as well as highly specialized quantitative methods and psychometrics will often not be a good fit to PS and should be submitted elsewhere. ${ }^{13}$ Third, papers reporting "one-shot findings" using a cross-sectional design and only self-report data from a smaller and relatively WEIRD undergraduate sample (without justification why these data from this sample are essential) will usually not be publishable. Lastly, reviews of textbooks and handbooks will also ordinarily not be considered.

\section{Reasons to Publish in and Review for Personality Science}

We believe there are several good reasons to send us your work and review for us. First, as PS is an online-only, diamond open-access journal, neither readers nor authors pay any fees. Thus, there are no financial barriers which especially benefits scholars from underrepresented and low-income countries or institutions. The journal, being funded in the long-term by the EAPP and ZPID and not subscribing to a commercial enterprise, does not generate any revenue or make profit off publications or subscriptions. However, to keep all aspects of the journal free of charge for everyone, there is a maximum number of pages that can be published each year. ${ }^{14}$ This meant a conscious decision to have shorter articles with recommended word, reference, table, and figure counts - rather than longer articles with no restrictions at all - so that more authors would be able to publish in PS. An implication of the limited space available per year is that articles need to conform to highest standards to be publishable. A such, PS will be a highly selective journal from the start, and having one's work accepted here will mean something.

Second, PS is tasked with the explicit mandate to increase diversity of samples, authors, and methodologies. Thus, the journal explicitly welcomes publications from disciplines other than psychology as well as from multi- or interdisciplinary consortia. Additionally, less WEIRD samples will be treated as a bonus when evaluating submissions.

12) These can be submitted to the sister journal, the European fournal of Personality (until December 2020: https:// onlinelibrary.wiley.com/journal/10990984; as of January 2021: https://journals.sagepub.com/home/erp).

13) They can be submitted to the open-access journals Psychological Test Adaptation and Development, Measurement Instruments for the Social Sciences, Methodology, or Quantitative and Computational Methods in Behavioral Sciences.

14) These refer to pages in final proofs. The exact number depends on several factors, most notably the limited resources of ZPID which is not a commercial publisher. It is hard to tell how many articles per year can be published because this depends on what categories and types of papers are accepted (each have a different length). A rough estimate would be that between 30 to 50 articles can be published per year. 
Lastly, the journal emphasizes its inclusive approach to conceptualizing, measuring, and studying any aspects of personality and individual differences, leaving all doors open.

Third, PS promotes open, transparent, reproducible, and rigorous research. By adopting and enforcing TOP guidelines, we want to ensure more trustworthiness of published content. Indeed, PS is currently the highest-ranked journal for personality psychology and among the highest-ranked journals in general in terms of its TOP factor. ${ }^{15}$ Empirical articles need to contain different statements on transparency, openness, and reproducibility (these will have to be marked in blue font in submissions to facilitate their detection). Upon submission of a manuscript to the journal system, an electronic Article Information Form (AIF) $)^{16}$ - modeled after a consensus-based transparency checklist (Aczel et al., 2020) - replaces the traditional cover letter, provides more standardization across submissions, and gathers vital information on openness and transparency implementations. Further, all submissions are required to use an official PS paper template ${ }^{17}$ which gathers basic information and again ensures a common and consistent standard across all submissions. In the interest of open and collaborative science, all accepted articles and supplements are published with a CC-BY 4.0 license, meaning that authors retain ownership of their work. This license makes it easier to re-use (parts of) articles, provided that the authors have been appropriately cited and credited. Supplements on PsychArchives are linked to in the paper, are permanently available, receive DOIs, are enriched with metadata, and have passed quality-control standards. This means that the supplements to an empirical paper do not just contain an unaudited "dump" of files; rather, these files have been screened, sensibly arranged, and conform to FAIR principles (i.e., they are findable, accessible, interoperable, and reusable).

Fourth, PS provides choices for authors and reviewers in different areas. For example, authors can choose to request a streamlined review process for papers rejected elsewhere, and they can also identify themselves to reviewers if they wish. Reviewers also have several choices available that are, in principle, independent of each other. Specifically, they can choose to (1) disclose their name to the authors in the confidential review process, (2) have their name indicated on the published paper (if accepted), and (3) have their review published alongside the paper (if accepted) as a supplement (though the authors need to agree to this also), with or without their name attached to that open review. PS does not formulate any requirements for reviewers to identify themselves, but signed reviews may have several benefits (Lynam et al., 2019). For the future, PS also plans to implement (moderated) post-publication peer-review, granting readers the choice to leave informed comments and insights on papers and authors the choice to respond.

\footnotetext{
15) See https://topfactor.org/

16) See https://ps.psychopen.eu/index.php/ps/author-guidelines

17) See https://ps.psychopen.eu/index.php/ps/about/submissions
} 
Fifth, PS offers novel and attractive paper formats (e.g., Insights \& Ideas, Projects \& Data, Cumulative Blitz Reports, Registered Reports, Controversy Exchanges). The journal was explicitly conceived to be nimble and adaptable to different or new kinds of papers and input from readers, authors, reviewers, and editors. As such, perhaps different or more formats may be offered in the future in response to requests to implement them.

Lastly, the journal has a dedicated team ${ }^{18}$ and support from both EAPP and ZPID with a long-term development plan for the journal. The inaugural team consists of three senior consultant members (Mitja Back, Verónica Benet-Martínez, Samuel Gosling), three methodological consultant members (Daniel Lakens, Daniel Leising, Felix Schönbrodt), 12 associate editors from different world regions and with gender parity (Anna Baumert, Ryan Hong, Martina Hřebíčková, Lauren Human, Claudio Hutz, Markus Jokela, Sumaya Laher, Carolyn MacCann, Atsushi Oshio, Marco Perugini, Ryne Sherman, Michelle Yik), an editorial assistant (Theresa Körnig), and an editor-in-chief and managing editor (John Rauthmann). Everyone is committed to ensuring the success of this journal and making it a place where good personality science can thrive.

\section{The Way Forward: Opening Doors - And Keeping Them Open}

In 1946, Allport maintained that "no doors should be closed in the study of personality" (pp. 133-134). This new journal wants to open all doors and keep them open to do personality science justice. Our goal for PS is to fully embrace and foster such epistemic diversity by growing a larger, more inclusive community of personality scientists around the world. In the beginning, this will constitute a multidisciplinary endeavor (i.e., studying personality from the lens of different disciplines, each using their own perspectives and methods). A next step will be working towards interdisciplinarity where common theories, questions, methods, and insights are developed, cutting across disciplinary borders. Going even further beyond, transdisciplinarity would be achieved once personality science has emerged as a truly integrated, seamless blend of various disciplines. Epistemic diversity is beneficial on many levels, but there need to be coordinated, unifying efforts to prevent approaches or entire research areas being neglected, drifting off, becoming too insular, or being barely integrated into a cumulative knowledge base. PS seeks to be such a coordinating force that contributes to uniting us in our diversity. We thus invite you to create an inclusive space with this journal where discourse is cross-cutting and integrative. Let us together build a bold and inspiring journal that serves, expands, and disseminates our rich field, personality science!

18) See their reasons for joining $P S$ and their visions at https://ps.psychopen.eu/index.php/ps/blurbs 
Funding: The author has no funding to report.

Competing Interests: The author has declared that no competing interests exist.

Acknowledgments: I thank members of the EAPP Executive Committee (Jaap Denissen, Anu Realo), ZPID team (Gerhard Eilbacher, Armin Günther), journal staff (Theresa Körnig), and the journal's Advisory Board (Mitja Back, Verónica Benet-Martínez, Sam Gosling, Daniel Lakens, Daniel Leising, Felix Schönbrodt) for guiding the development and launch of the journal as well as providing helpful feedback and input on this editorial.

\section{References}

Aczel, B., Szaszi, B., Sarafoglou, A., Kekecs, Z., Kucharský, S., Benjamin, D., . . Wagenmakers, E. J. (2020). A consensus-based transparency checklist. Nature Human Behaviour, 4, 4-6. https://doi.org/10.1038/s41562-019-0772-6

Allik, J. (2013). Personality psychology in the first decade of the new millennium: A bibliometric portrait. European fournal of Personality, 27, 5-14. https://doi.org/10.1002/per.1843

Allik, J., Lauk, K., \& Realo, A. (2020). Factors predicting the scientific wealth of nations. CrossCultural Research, 54, 364-397. https://doi.org/10.1177/1069397120910982

Allport, G. W. (1946). Personalistic psychology as science: A reply. Psychological Review, 53, 132-135. https://doi.org/10.1037/h0058477

Allport, G. W. (1961). Pattern and growth in personality. Holt, Rinehart \& Winston.

AlShebli, B. K., Rahwan, T., \& Woon, W. L. (2018). The preeminence of ethnic diversity in scientific collaboration. Nature Communications, 9, Article 5163. https://doi.org/10.1038/s41467-018-07634-8

Apicella, C., Norenzayan, A., \& Henrich, J. (2020). Beyond WEIRD: A review of the last decade and a look ahead to the global laboratory of the future. Evolution and Human Behavior, 41, 319-329. https://doi.org/10.1016/j.evolhumbehav.2020.07.015

Arnett, J. J. (2008). The neglected 95\%: Why American psychology needs to become less American. The American Psychologist, 63, 602-614. https://doi.org/10.1037/0003-066X.63.7.602

Atherton, O. E., \& Robins, R. W. (2020, November 20). The Personality Development Collaborative. https://www.personalitydevelopmentcollaborative.org

Beck, E. D., \& Jackson, J. J. (2020, November 2). A mega-analysis of personality prediction: Robustness and boundary conditions. PsyArXiv. https://doi.org/10.31234/osf.io/7pg9b

Bélisle, J. F., \& Bodur, H. O. (2010). Avatars as information: Perception of consumers based on their avatars in virtual worlds. Psychology and Marketing, 27, 741-765. https://doi.org/10.1002/mar.20354

Bell, A. M., Hankison, S. J., \& Laskowski, K. L. (2009). The repeatability of behaviour: A metaanalysis. Animal Behaviour, 77, 771-783. https://doi.org/10.1016/j.anbehav.2008.12.022 
Bleidorn, W., Hill, P. L., Back, M. D., Denissen, J. J. A., Hennecke, M., Hopwood, C. J., . . Roberts, B. (2019). The policy relevance of personality traits. The American Psychologist, 74, 1056-1067. https://doi.org/10.1037/amp0000503

Bremner, P., Celiktutan, O., \& Gunes, H. (2016, March). Personality perception of robot avatar teleoperators. In 2016 11th ACM/IEEE International Conference on Human-Robot Interaction (HRI) (pp. 141-148). IEEE.

Broadbent, E., Kumar, V., Li, X., Sollers, J., III, Stafford, R. Q., MacDonald, B. A., \& Wegner, D. M. (2013). Robots with display screens: A robot with a more humanlike face display is perceived to have more mind and a better personality. PLoS One, 8, Article e72589.

https://doi.org/10.1371/journal.pone.0072589

Carere, C., \& Maestripieri, D. (Eds.). (2013). Animal personalities: Behavior, physiology, and evolution. University of Chicago Press.

Chartier, C. R., Riegelman, A., \& McCarthy, R. J. (2018). StudySwap: A platform for interlab replication, collaboration, and resource exchange. Advances in Methods and Practices in Psychological Science, 1, 574-579. https://doi.org/10.1177/2515245918808767

Cheek, N. N. (2017). Scholarly merit in a global context: The nation gap in psychological science. Perspectives on Psychological Science, 12, 1133-1137. https://doi.org/10.1177/1745691617708233

Churamani, N., Barros, P., Gunes, H., \& Wermter, S. (2020). Affect-driven modelling of robot personality for collaborative human-robot interactions [Preprint, arXiv:2010.07221]. arXiv. https://arxiv.org/abs/2010.07221

Cloninger, S. (2020). Conceptual and historical perspectives. In P. J. Corr \& G. Matthews (Eds.), The Cambridge handbook of personality psychology (2nd ed., pp. 13-30). Cambridge University Press.

Colom, R., Bensch, D., Horstmann, K. T., Wehner, C., \& Ziegler, M. (2019). Special Issue "The Ability-Personality Integration”. Journal of Intelligence, 7, Article 13. https://doi.org/10.3390/jintelligence7020013

Craenen, B., Deshmukh, A., Foster, M. E., \& Vinciarelli, A. (2018, August). Do we really like robots that match our personality? The case of Big-Five traits, Godspeed scores and robotic gestures. In 2018 27th IEEE International Symposium on Robot and Human Interactive Communication (RO$M A N)$ (pp. 626-631). IEEE.

Dall, S. R., Houston, A. I., \& McNamara, J. M. (2004). The behavioural ecology of personality: Consistent individual differences from an adaptive perspective. Ecology Letters, 7, 734-739. https://doi.org/10.1111/j.1461-0248.2004.00618.x

Devezer, B., Nardin, L. G., Baumgaertner, B., \& Buzbas, E. O. (2019). Scientific discovery in a modelcentric framework: Reproducibility, innovation, and epistemic diversity. PLoS One, 14, Article e0216125. https://doi.org/10.1371/journal.pone.0216125

DeYoung, C. G., Chmielewski, M., Clark, L. A., Condon, D. M., Kotov, R., Krueger, R. F., . . the HiTOP Normal Personality Workgroup. (2020). The distinction between symptoms and traits in the Hierarchical Taxonomy of Psychopathology (HiTOP). fournal of Personality. Advance online publication. https://doi.org/10.1111/jopy.12593 
Diener, E., Oishi, S., \& Park, J. (2014). An incomplete list of eminent psychologists of the modern era. Archives of Scientific Psychology, 2, 20-32. https://doi.org/10.1037/arc0000006

Ebersole, C. R., Andrighetto, L., Casini, E., Chiorri, C., Dalla Rosa, A., Domaneschi, F., . . Richetin, E., JVianello, M. (2020). Many Labs 5: Registered replication of Payne, Burkley, and Stokes (2008), Study 4. Advances in Methods and Practices in Psychological Science, 3, 387-393. https://doi.org/10.1177/2515245919885609

Fong, K., \& Mar, R. A. (2015). What does my avatar say about me? Inferring personality from avatars. Personality and Social Psychology Bulletin, 41, 237-249. https://doi.org/10.1177/0146167214562761

Fournier, M. A., Di Domenico, S. I., Weststrate, N. M., Quitasol, M. N., \& Dong, M. (2015). Toward a unified science of personality coherence. Canadian Psychology, 56, 253-262. https://doi.org/10.1037/cap0000022

Funder, D. C. (2015). The personality puzzle (8th ed.). W. W. Norton \& Company.

Graham, E. K., Weston, S. J., Gerstorf, D., Yoneda, T. B., Booth, T., Beam, C. R., . . Mroczek, D. K. (2020). Trajectories of Big Five personality traits: A coordinated analysis of 16 longitudinal samples. European fournal of Personality, 34(3), 301-321. https://doi.org/10.1002/per.2259

Green, B. N., \& Johnson, C. D. (2015). Interprofessional collaboration in research, education, and clinical practice: Working together for a better future. The fournal of Chiropractic Education, 29, 1-10. https://doi.org/10.7899/JCE-14-36

Haggbloom, S. J., Warnick, R., Warnick, J. E., Jones, V. K., Yarbrough, G. L., Russel, R. M., . . Monte, E. (2002). The 100 most eminent psychologists of the 20th century. Review of General Psychology, 6, 139-152. https://doi.org/10.1037/1089-2680.6.2.139

Harzing, A. W., \& Giroud, A. (2014). The competitive advantage of nations: An application to academia. Journal of Informetrics, 8, 29-42. https://doi.org/10.1016/j.joi.2013.10.007

Hengartner, M. P., Kawohl, W., Haker, H., Rössler, W., \& Ajdacic-Gross, V. (2016). Big Five personality traits may inform public health policy and preventive medicine: Evidence from a cross-sectional and a prospective longitudinal epidemiologic study in a Swiss community. fournal of Psychosomatic Research, 84, 44-51. https://doi.org/10.1016/j.jpsychores.2016.03.012

Henrich, J., Heine, S. J., \& Norenzayan, A. (2010). Beyond WEIRD: Towards a broad-based behavioral science. Behavioral and Brain Sciences, 33, 61-135.

https://doi.org/10.1017/S0140525X0999152X

Hofstra, B., Kulkarni, V. V., Galvez, S. M. N., He, B., Jurafsky, D., \& McFarland, D. A. (2020). The diversity-innovation paradox in science. Proceedings of the National Academy of Sciences of the United States of America, 117, 9284-9291. https://doi.org/10.1073/pnas.1915378117

Hogan, R. (2007). Personality and the fate of organizations. Lawrence Erlbaum Associates.

Hogan, R., \& Sherman, R. A. (2020). Personality theory and the nature of human nature. Personality and Individual Differences, 152, Article 109561. https://doi.org/10.1016/j.paid.2019.109561

Hong, L., \& Page, S. E. (2004). Groups of diverse problem solvers can outperform groups of highability problem solvers. Proceedings of the National Academy of Sciences of the United States of America, 101, 16385-16389. https://doi.org/10.1073/pnas.0403723101 
IJzerman, H., Lewis, N. A., Przybylski, A. K., Weinstein, N., DeBruine, L., Ritchie, S. J., . . Anvary, F. (2020). Use caution when applying behavioural science to policy. Nature Human Behaviour, 4, 1092-1094. https://doi.org/10.1038/s41562-020-00990-w

Joel, S., Eastwick, P. W., Allison, C. J., Arriaga, X. B., Baker, Z. G., Bar-Kalifa, E., . . Wolf, S. (2020). Machine learning uncovers the most robust self-report predictors of relationship quality across 43 longitudinal couples studies. Proceedings of the National Academy of Sciences, 117, 19061-19071. https://doi.org/10.1073/pnas.1917036117

Kandler, C., Penner, A., Richter, J., \& Zapko-Willmes, A. (2019). The Study of Personality Architecture and Dynamics (SPeADy): A longitudinal and extended twin family study. Twin Research and Human Genetics, 22, 548-553. https://doi.org/10.1017/thg.2019.62

Klein, R. A., Vianello, M., Hasselman, F., Adams, B. G., Adams, R. B., Jr., Alper, S., . . Neijenhuis, K. (2018). Many Labs 2: Investigating variation in replicability across samples and settings. Advances in Methods and Practices in Psychological Science, 1, 443-490. https://doi.org/10.1177/2515245918810225

Kliegl, R., \& Bates, D. (2011). International collaboration in psychology is on the rise. Scientometrics, 87, 149-158. https://doi.org/10.1007/s11192-010-0299-0

Lanning, K. (2017). What is the relationship between "personality" and "social" psychologies? Network, community, and whole text analyses of the structure of contemporary scholarship. Collabra: Psychology, 3(1), Article 8. https://doi.org/10.1525/collabra.70

Larsen, R., \& Buss, D. M. (2021). Personality psychology: Domains of knowledge about human nature (7th ed.). McGraw Hill.

Liddell, H. G., \& Scott, R. (1940). A Greek-English Lexicon. Revised and augmented throughout by Sir Henry Stuart Jones, with the assistance of Roderick McKenzie. Clarendon Press. Entry on $\psi v \chi \eta \dot{~}$

http://www.perseus.tufts.edu/hopper/text? doc=Perseus\%3Atext\%3A1999.04.0057\%3Aentry\%3Dyuxh\%2F

Lynam, D. R., Hyatt, C. S., Hopwood, C. J., Wright, A. G. C., \& Miller, J. D. (2019). Should psychologists sign their reviews? Some thoughts and some data. fournal of Abnormal Psychology, 128, 541-546. https://doi.org/10.1037/abn0000426

McAdams, D. P. (1997a). The case for unity in the (post)modern self: A modest proposal. In R. Ashmore \& L. Jussim (Eds.), Self and identity: Fundamental issues (pp. 46-78). Oxford University Press.

McAdams, D. P. (1997b). A conceptual history of personality psychology. In R. Hogan, J. Johnson, \& S. Briggs (Eds.), Handbook of personality psychology (pp. 3-39). Academic Press.

McAdams, D. P., \& Pals, J. L. (2006). A new Big Five: Fundamental principles for an integrative science of personality. The American Psychologist, 61, 204-217. https://doi.org/10.1037/0003-066X.61.3.204

McAdams, D. P., \& Pals, J. L. (2007). The role of theory in personality research. In R. W. Robins, R. C. Fraley, \& R. F. Krueger (Eds.), Handbook of research methods in personality psychology (pp. 3-20). The Guilford Press. 
McLeod, P. L., Liu, Y. C., \& Axline, J. E. (2014). When your Second Life comes knocking: Effects of personality on changes to real life from virtual world experiences. Computers in Human Behavior, 39, 59-70. https://doi.org/10.1016/j.chb.2014.06.025

Medin, D., Ojalehto, B., Marin, A., \& Bang, M. (2017). Systems of (non-)diversity. Nature Human Behaviour, 1, Article 0088. https://doi.org/10.1038/s41562-017-0088

Morf, C. C. (2002). Personality at the hub: Extending the conception of personality psychology. fournal of Research in Personality, 36, 649-660. https://doi.org/10.1016/S0092-6566(02)00517-2

Moshontz, H., Campbell, L., Ebersole, C. R., IJzerman, H., Urry, H. L., Forscher, P. S., . . Chartier, C. R. (2018). The Psychological Science Accelerator: Advancing psychology through a distributed collaborative network. Advances in Methods and Practices in Psychological Science, 1, 501-515. https://doi.org/10.1177/2515245918797607

Munafò, M. R., Nosek, B. A., Bishop, D. V., Button, K. S., Chambers, C. D., Du Sert, N. P., . . Ioannidis, J. P. (2017). A manifesto for reproducible science. Nature Human Behaviour, 1, Article 0021. https://doi.org/10.1038/s41562-016-0021

Nosek, B. A., Beck, E. D., Campbell, L., Flake, J. K., Hardwicke, T. E., Mellor, D. T., . . Vazire, S. (2019). Preregistration is hard, and worthwhile. Trends in Cognitive Sciences, 23, 815-818. https://doi.org/10.1016/j.tics.2019.07.009

O'Dea, R. E., Noble, D. W., \& Nakagawa, S. (2020, August 23). Unifying individual differences in personality, predictability, and plasticity: A practical guide. EcoEvoRxiv.

https://doi.org/10.32942/osf.io/bnugw

Ozer, D. J., \& Benet-Martínez, V. (2006). Personality and the prediction of consequential outcomes. Annual Review of Psychology, 57, 401-421. https://doi.org/10.1146/annurev.psych.57.102904.190127

Page, S. E. (2008). The difference: How the power of diversity creates better groups, firms, schools, and societies. Princeton University Press.

Pan, X., Gillies, M., \& Slater, M. (2015). Virtual character personality influences participant attitudes and behavior - An interview with a virtual human character about her social anxiety. Frontiers in Robotics and AI, 2, Article 1. https://doi.org/10.3389/frobt.2015.00001

Rad, M. S., Martingano, A. J., \& Ginges, J. (2018). Toward a psychology of Homo sapiens: Making psychological science more representative of the human population. Proceedings of the National Academy of Sciences of the United States of America, 115, 11401-11405. https://doi.org/10.1073/pnas.1721165115

Read, S. J., \& Miller, L. C. (2002). Virtual personalities: A neural network model of personality. Personality and Social Psychology Review, 6, 357-369. https://doi.org/10.1207/S15327957PSPR0604_10

Reich, N., \& Eyssel, F. (2013). Attitudes towards service robots in domestic environments: The role of personality characteristics, individual interests, and demographic variables. Paladyn: Journal of Behavioral Robotics, 4, 123-130. https://doi.org/10.2478/pjbr-2013-0014 
Renner, K. H., \& Laux, L. (2000). Unitas multiplex, purposiveness, individuality: Contrasting Stern's conception of the person with Gergen's saturated self. Theory \& Psychology, 10, 831-846. https://doi.org/10.1177/0959354300106008

Revelle, W. (2007). Experimental approaches to the study of personality. In R. W. Robins, R. C. Fraley, \& R. F. Krueger (Eds.), Handbook of research methods in personality psychology (p. 37-61). The Guilford Press.

Robert, L. P. (2018). Personality in the human robot interaction literature: A review and brief critique. In Proceedings of the 24th Americas Conference on Information Systems, Aug 16-18. New Orleans, LA. https://ssrn.com/abstract=3308191

Roberts, B. W., Kuncel, N. R., Shiner, R., Caspi, A., \& Goldberg, L. R. (2007). The power of personality: The comparative validity of personality traits, socioeconomic status, and cognitive ability for predicting important life outcomes. Perspectives on Psychological Science, 2, 313-345. https://doi.org/10.1111/j.1745-6916.2007.00047.x

Robins, R. W., Tracy, J. L., \& Sherman, J. W. (2007). What kinds of methods do personality psychologists use? A survey of journal editors and editorial board members. In R. W. Robins, R. C. Fraley, \& R. F. Krueger (Eds.), Handbook of research methods in personality psychology (pp. 673-678). The Guilford Press.

Sih, A., Bell, A., \& Johnson, J. C. (2004). Behavioral syndromes: An ecological and evolutionary overview. Trends in Ecology \& Evolution, 19, 372-378. https://doi.org/10.1016/j.tree.2004.04.009

Sih, A., Mathot, K. J., Moirón, M., Montiglio, P. O., Wolf, M., \& Dingemanse, N. J. (2015). Animal personality and state-behaviour feedbacks: A review and guide for empiricists. Trends in Ecology \& Evolution, 30, 50-60. https://doi.org/10.1016/j.tree.2014.11.004

Sih, A., Munson, A., \& Pollack, L. (2020). Animal personalities. In The Wiley Encyclopedia of personality and individual differences: Models and theories (pp. 117-122). Wiley-Blackwell.

Simons, D. J., Shoda, Y., \& Lindsay, D. S. (2017). Constraints on Generality (COG): A proposed addition to all empirical papers. Perspectives on Psychological Science, 12, 1123-1128. https://doi.org/10.1177/1745691617708630

Smaldino, P., \& O’Connor, C. (2020, November 5). Interdisciplinarity can aid the spread of better methods between scientific communities. MetaArXiv. https://doi.org/10.31222/osf.io/cm5v3

Soderberg, C. K., Errington, T. M., Schiavone, S. R., Bottesini, J. G., Singleton Thorn, F., Vazire, S., Esterling, K. E., \& Nosek, B. A. (2020, November 16). Research quality of registered reports compared to the traditional publishing model. MetaArXiv. https://doi.org/10.31222/osf.io/7x9vy

Soto, C. J. (2019). How replicable are links between personality traits and consequential life outcomes? The Life Outcomes of Personality Replication Project. Psychological Science, 30, 711-727. https://doi.org/10.1177/0956797619831612

Soto, C. J. (2021). Do links between personality and life outcomes generalize? Testing the robustness of trait-outcome associations across gender, age, ethnicity, and analytic approaches. Social Psychological \& Personality Science, 12, 118-130. https://doi.org/10.1177/1948550619900572 Spadaro, G., Tiddi, I., Columbus, S., Jin, S., ten Teije, A., \& Balliet, D. (2020, October 28). The Cooperation Databank. PsyArXiv. https://doi.org/10.31234/osf.io/rveh3 
Stember, M. (1991). Advancing the social sciences through the interdisciplinary enterprise. The Social Science fournal, 28, 1-14. https://doi.org/10.1016/0362-3319(91)90040-B

Stern, W. (1923). Die menschliche Persönlichkeit. Band 2 von: Person und Sache. System des kritischen Personalismus. Barth.

Tackett, J. L., Herzhoff, K., Balsis, S., \& Cooper, L. (2016). Toward a unifying perspective on personality pathology across the life span. In D. Cicchetti (Ed.), Developmental psychopathology: Maladaptation and psychopathology (pp. 1039-1078). John Wiley \& Sons.

Thalmayer, A. G., Toscanelli, C., \& Arnett, J. J. (2020). The neglected 95\% revisited: Is American psychology becoming less American? The American Psychologist. Advance online publication. https://doi.org/10.1037/amp0000622

Thelwall, M., \& Levitt, J. M. (2018). National scientific performance evolution patterns: Retrenchment, successful expansion, or overextension. Journal of the Association for Information Science and Technology, 69, 720-727. https://doi.org/10.1002/asi.23969

Tracy, J. L., Robins, R. W., \& Sherman, J. W. (2009). The practice of psychological science: Searching for Cronbach's two streams in social-personality psychology. Fournal of Personality and Social Psychology, 96, 1206-1225. https://doi.org/10.1037/a0015173

Ünal, S., Dalgiç, T., \& Akar, E. (2018). Avatars as the virtual world's personality. In E. Başar, A. Erciş, \& S. Ünal (Eds.), The virtual world and marketing (pp. 33-53). Cambridge Scholars Publishing.

Vazire, S. (2018). Implications of the credibility revolution for productivity, creativity, and progress. Perspectives on Psychological Science, 13, 411-417. https://doi.org/10.1177/1745691617751884

Wolf, M., \& Weissing, F. J. (2012). Animal personalities: Consequences for ecology and evolution. Trends in Ecology \& Evolution, 27, 452-461. https://doi.org/10.1016/j.tree.2012.05.001

Yang, Y. J., \& Chiu, C. Y. (2009). Mapping the structure and dynamics of psychological knowledge: Forty years of APA journal citations (1970-2009). Review of General Psychology, 13, 349-356. https://doi.org/10.1037/a0017195

\section{edpp $\begin{aligned} & \text { European Association of } \\ & \text { Personality Psychology }\end{aligned}$}

Personality Science is an official journal of the European Association of Personality Psychology (EAPP). 